\title{
DISCLAIMER
}

This report was prepared as an account of work sponsored by an agency of the United States Government. Neither the Untited States (jovernmenl nor any agency thereor, nor any of their employecs, makes any warranty. express or implicd, or assumes any legal liability or responsibility for the accueacy, compleleness, or uscfulness of any informalion, apparatus, product, or process diselosed, or represents that its use would not infringe privately owned eights. Refer. ence hercin to any specific commercial producl, process, or service by trade name, trademark, manufaclurer, or otherwisc does not necessarify constitute or inply its endorsement, recommendation, or favoring by the United States Government or any agency thereof. The views and opinions of authors expressed herein do not necessarily siate or reflect those of the United Siates Government or any agency thereof.

\section{Damping of electron cyclotron waves in dense plasmas of a Compact Ignition Tokamak}

\author{
E. Mazzucato, I. Fidone ${ }^{a}$, and G. Granata ${ }^{a}$ \\ Princeton University, Plasma Physics Laboratory \\ Princeton, N. J. 08544
}

PPPL --2453

DE87 013198

\begin{abstract}
Absorption of electromagnetic waves by hot and dense plasmas is investigated in the electron cyclotron range of frequency. It is shown that the strong reduction of the damping of the extraordinary mode, caused by finite Larmor radius effects on waves propagating perpendicularly to the magnetic field, becomes insignificant at large values of the parallel component of the refractive index.

With an appropriate form of the relativistic dispersion relation which includes high order Larmor radius terms, heating of dense plasmas in a Compact Ignition Tolamak is investigated. It is shown that by using the extraordinary mode with oblique propagation and frequency of $190 \mathrm{GHz}$ it is possible to bring to thermonuclear ignition a dense ohmic plasma with a toroidal magnetic field of $105 \mathrm{kG}$ and a central density of $1 \times 10^{15} \mathrm{~cm}^{-3}$.
\end{abstract}

${ }^{a}$ Permanent address: Association Euratom-C.E.A., C.E.N.-Cadarache, France. 


\section{Introduction}

Recently, ${ }^{1-4}$ the linear theory of cleciron cyclotron waves, approximated to the lowest significant order in the Larmor radius, has bcen used for the study of plasma absorption of extraordinary waves propagating obliquely to the magnetic ficld with frequency $\omega$ significantly smaller than the electron cyclotron frequency $\omega_{c}$. This type of wave absorption offers several advantages: It minimizes the wave frequency for a given value of magnetic field, which makes possible the use of existing high power sources in present large tokamaks. ${ }^{2}+4$ It maximizes the plasma density for a given walue cit $\omega$, which makes it suitable for hoating high $\beta$ plasmas. It minimizes trapped particle effects in tokamaks, since the wave is absorbed by passing electrons. Finally, it allows control of the power deposition in both the physical and the velocity space, which can be used for profile control or current drive in tokamaks.

The damping of electron cyclotron waves in hot and dense plasmas, as those considered in Refs. 1-4, can be affected by finite Larmor radius (FLR) effects. It has been shown previously ${ }^{5}$ that plasma absorption of electromagnetic waves propagating perpendicularly to the magnetic field with the extraordinary mode is strongly reduced by FLR effects when the plasma frequency $\omega_{p} \approx \omega_{c} \approx \omega$. In this article we address the same issue for arbitrary values of the parallel refractive index $N_{\| l}$. Section II presents the relativistic dispersion relation of electron cyclotron waves with arbitrary values of $N_{\|}$in hot Maxwellian plasmas. In Sec. III we study the solution of the dispersion equation for the extraordinary mode with frequency around the electron cyclotron frequency. Section $I V$ discusses the issue of auxiliary heating in the Compact Ignition Tokamak ${ }^{6}(\mathrm{CIT})$, and Sec. V presents numerical results on the absorption of electron cyclotron waves by dense CIT plasmas with a toroidal magnetic field of $105 \mathrm{kG}$ and a wave frequency of $190 \mathrm{GHz}$. Finally, our conclusions are summarized in Sec. VI.

\section{The dispersion relation}

The relativistic dispersion relation of electron cyclotron waves in a Maxwellian plasma has been discussed in several articles. Here we use a form derived recently, ${ }^{7}$ which is particularly useful for investigating the absorption of waves with oblique propagation.

A power series expansion of the dielectric tensor with terms of up to second order in Larmor radius was derived in Ref. 7. In this paper we add the next significant order terms, which we have found important for 
a correct description of the damping of electron cyclotron waves in dense plasmas.

In the orthogonal frame of reference with basis $\left(\mathbf{e}_{1}, \mathbf{e}_{2}, \mathbf{e}_{3}\right)$, where the magnetic field $\mathbf{B}=\mathrm{Be}_{3}$ and the complex index of refraction $\mathbf{N}=N_{\perp} \mathbf{e}_{1}+$ $N_{\|} \mathbf{e}_{3}$, the gencral form of the dispersion relation is given by the equation

$$
\begin{aligned}
D & \equiv \epsilon_{11} N_{\perp}^{4}+2 N_{\|} \epsilon_{13} N_{\perp}^{3} \\
& +N_{\perp}^{2}\left(\epsilon_{13}^{2}+N_{\|}^{2} \epsilon_{11}-\epsilon_{11} \epsilon_{22}-\epsilon_{12}^{2}+N_{\|}^{2} \epsilon_{33}-\epsilon_{11} \epsilon_{33}\right) \\
& +2 N_{\|} N_{\perp}\left(N_{\|}^{2} \epsilon_{13}-\epsilon_{22} \epsilon_{13}+\epsilon_{12} \epsilon_{23}\right)+\epsilon_{11} \epsilon_{23}^{2}-\epsilon_{22} \epsilon_{13}^{2}+2 \epsilon_{12} \epsilon_{13} \epsilon_{23} \\
& +N_{\|}^{2}\left(\epsilon_{13}^{2}-\epsilon_{23}^{2}\right)+N_{\|}^{2} \epsilon_{33}\left(N_{\|}^{2}-\epsilon_{11}-\epsilon_{22}\right)+\epsilon_{23}\left(\epsilon_{12}^{2}+\epsilon_{11} \epsilon_{22}\right)=0,
\end{aligned}
$$

where $\epsilon_{i j}=\epsilon_{i j}^{\prime}+i \epsilon_{i j}^{\prime \prime}$ are the components of the hot plasma dielectric tensor. The Hermitian part $\epsilon_{i j}^{\prime}$ was given in Ref. 7 and is not presented here. For the anti-Hermitian part one obtains

$$
\begin{aligned}
& \left.\epsilon_{11}^{\prime \prime}=a_{11}+N_{\perp}^{2}\left(b_{11}+c_{11}\right)+N_{\perp}^{4} i d_{11}+f_{11}+g_{11}\right), \\
& \epsilon_{12}^{\prime \prime}=-i\left[a_{11}+N_{\perp}^{2}\left(2 b_{11}+c_{11}\right)+N_{\perp}^{4}\left(3 d_{11}+3 f_{11} / 2+g_{11}\right)\right], \\
& \epsilon_{22}^{\prime \prime}=a_{11}+N_{\perp}^{2}\left(3 b_{11}+c_{11}\right)+N_{\perp}^{4}\left(37 d_{11} / 5+2 f_{11}+g_{11}\right), \\
& \epsilon_{13}^{\prime \prime}=N_{\perp}\left[a_{13}+N_{\perp}^{2}\left(b_{13}+c_{13}\right)+N_{\perp}^{4}\left(d_{13}+f_{13}+g_{13}\right)\right], \\
& \epsilon_{23}^{\prime \prime}=i N_{\perp}\left[a_{13}+N_{\perp}^{2}\left(2 b_{13}+c_{13}\right)+N_{\perp}^{4}\left(3 d_{13}+3 f_{13} / 2+g_{13}\right)\right], \\
& \epsilon_{33}^{\prime \prime}=N_{\perp}^{2}\left[a_{33}+N_{\perp}^{2}\left(b_{33}+c_{33}\right)+N_{\perp}^{4}\left(d_{33}+f_{33}+g_{33}\right)\right] .
\end{aligned}
$$

These expressions contain the contribution of the first $\left(a_{i j}, b_{i j}, d_{i j}\right)$, the second $\left(c_{i j}, f_{i j}\right)$, and the third $\left(g_{i j}\right)$ harmonic of the electron cyclotron frequency, and are therefore valid whenever the effect of the fourth harmonic is negligible, i.e., for thermal plasmas with $T_{e} \leq 50 \mathrm{keV}$ when $\omega<\omega_{c}$.

The various terms of Eq. (2) are given in the Appendix. Here we note that every coefficient in these equations contains a factor of type $F(p)=$ $\exp [-\mu(\gamma-1)]$, with $\mu=m c^{2} / T_{e}, \gamma=\left(1+p^{2}\right)^{1 / 2}$, and $p$ a solution of the resonant equation

$$
\left(1+p^{2}\right)^{1 / 2}-n \omega_{c} / \omega=N_{\|} p
$$

where $n$ is the harmonic number. It is this factor that makes the use of the relativistic theory essential for a correct description of electron cyclotron wave absorption even in plasmas with $T_{e}<<m c^{2}$. 


\section{Numerical results}

Our previous results ${ }^{1-4}$ were obtained with a reduced dispersion relation, where only the lowest order terms $\left(a_{i j}\right)$ were used in the dielectric tensor. In this section we shall investigate the validity of this approximation.

The imaginary parts of $N_{\perp}$ given by the reduced and the full dispersion relation are shown in Fig. 1 and 2 as a function of $\left(\omega_{p} / \omega\right)^{2}$ for the extraordinary mode with $\omega_{c} / \omega=1.3, T_{e}=20 \mathrm{keV}$, and with $N_{\|}=0$ and $N_{\|}=0.5$, respectively. In agreement with Ref. 5 , we find that high order FLR terms cause a reduction of the wave damping.

The ratio of the two results (full/reduced) is shown in Fig. 3 as a function of $\left(\omega_{p} / \omega\right)^{2}$ for the same plasma parameters and for several values of $N_{\|}$. It appears that the contribution of high order FLR terms, which for perpendicular propagation causes a strong reduction of wave damping at large values of $\left(\omega_{p} / \omega\right)^{2}$, becomes rapidly insignificant as the value of $N_{\|}$ increases. This is also shown by Fig. 4 , where the ratio is displayed as a function of $N_{\|}$for several values of $T_{e}$. From these results it appears that for the case of perpendicular propagation the FLR cffect is not very sensitive to the value of electron temperature. It is also a weak finction of $\omega_{c} / \omega$, as shown by Fig. 5 where the ratio is plotted for several values of this parameter.

Finally, in agreement with Ref. 5 we have found that in the same range of plasma parameters the contribution of high order FLR terms to the dispersion of ordinary waves is always negligeable for $\omega<\omega_{c}$.

In conclusion, the results of Refs. 1-4, where the plasma absorption of electron cyclotron waves with large frequency downshift and strong oblique propagation was investigated, are only slightly modified by the inclusion of high order FLR terms in the wave dispersion relation. Nevertheless, in applying this heating scheme to reactorlike plasmas, one is forced to consider wave propagation close to perpendicular for the sake of achieving accessibility to the highest values of plasma density which are allowed by a given value of wave frequency. In this case the full dispersion relation, Fq. (2), must be used for a correct description of wave absorption. This is the topic of the remainder of this paper where we investigate the absorption of electron cyclotron waves at downshifted frequency in the dense plasmas of a Compact Ignition Tokamak ${ }^{6}$ (CIT).

\section{TV. Auxiliary Heating in CIT}

CIT is a small, high field tokamak experiment designed to study the 
physics of $\alpha$-particle heating. ${ }^{6}$ It is expected that a large toroidal magnetic field $(\approx 1.00 \mathrm{kG})$ will allow the values of plasma density $\left(10^{15} \mathrm{~cm}^{-3}\right)$ and current $(10 M A)$ which are needed for reaching thermomclcar ignition in a small device. Auxiliary heating is expected to be neccssary as woll, but transport studies ${ }^{8}$ indicate that it will also be necessary either to avoid the deterioration in confinement caused by auxiliary heating ( $\mathrm{H}$-mode), or to control very carefully plasma density and temperature profiles.

ICRF has been selected for CIT. $^{6}$ Unfortunately, the use of this type of auxiliary heating under CIT plasma conditions faces two major obstacles:

(a) the plasma coupling of the fast magnetosonic wave is extremely sensitive to plasma edge conditions which are very difficult to control;

(b) with ICRF it is difficult to control the spatial distribution of the energy absorbed by the plasma, especially in the presence of a large $\alpha$-particle component.

In this article we suggest that Electron Cyclotron Heating (ECH) at down shifted frequency be also consjdered a viable candidate for CIT. The plasma coupling of electron cyclotron waves is not sensitive to plasma edge conditions or to $\alpha$ particles, and, more importantly, with this type of plasina waves it is possible to control the electronic power deposition profile in both the physical and the velocity space, a crucial requirement for profile control in tolamaks.

\section{ECH in CIT}

The use of a self-consistent magnetic configuration is important for a correct description of ECH in Tokamaks, since the damping of electron cyclotron waves is very sensitive to the amplitude and direction of the magnetic field which is modified by plasma current and pressure.

The CIT magnetic configuration has been modelled by solving the Grad-Shafranov equation for the poloidal magnetic flux $(2 \pi \psi)$

$$
\nabla \cdot\left(\nabla \psi / R^{2}\right)=-d p / d \psi-\left(F / R^{2}\right) d F / d \psi,
$$

with the plasma pressure $(p)$ and the poloidal current flux $(2 \pi F)$ given by $p=p_{1} \psi^{2}+p_{0}$, and $F^{2}=f_{1} \psi^{2}+f_{0}$, respectively. This choice of flux surface functions reduces the problem to the solution of an ordinary differential equation.

Fignure 6 shows an example of a CIT magnetic configuration with a vacuum toroidal magnetic field $B_{0}=105 k G$ at $R=125 \mathrm{~cm}$, and a volume average beta $\langle\beta\rangle=0.05$. With a plasma current $I=8.0 \mathrm{MA}$, the value 
of the safety factor $q$ is 1.0 on axis and 3.5 on the outmost magnetic surface shown in. Fig. 6. If the central electron density $n_{e}(0)=1 \times 10^{15} \mathrm{~cm}^{-3}$, we get $T_{e}(0)=T_{i}(0)=24 \mathrm{keV}$.

The wave trajectory was obtained from the familiar ray equations ${ }^{9}$

$$
\begin{aligned}
& \frac{d \mathbf{r}}{d s}=-\frac{\partial H / \partial \mathbf{k}}{|\partial H / \partial \mathbf{k}|}, \\
& \frac{d \mathbf{k}}{d s}=\frac{\partial H / \partial \mathbf{r}}{|\partial H / \partial \mathbf{k}|},
\end{aligned}
$$

where $\mathbf{r}$ is the spatial coordinate, $s$ is the arc length along the ray, and $\mathbf{k}=\mathbf{N} \omega / c$ is the wave vector. The function $H$ in Eq. (4) is the real part of $D$ of Eq. (1), which in the range of electron temperature considered in this paper is well approximated by the cold plasma theory.

The fraction of power which is absorbed by the plasma is given by

$$
P(s)=1-\exp \left(-2 \int_{0}^{s} \mathbf{k}^{i} \cdot \frac{d \mathbf{r}}{d s}\right),
$$

where the integral is along the ray, and $\mathbf{k}^{i}$ is obtained from the imaginary part of the solution of Eq. (1).

Some examples of ray trajectories are given in Fig. 6. Here waves with the extraordinary mode and a frequency of $190 \mathrm{GHz}$ are launched into a CIT discharge, with the plasma parameters listed above, from two different antennas: one located on top of the torus and the other near the equatorial plane. The rays of Fig. 6, which are labelled with the initial toroidal $\left(N_{t}=\sin \alpha\right)$ and poloidal $\left(N_{p}=\sin \beta\right)$ component of $\mathrm{N}$, have $\alpha=12^{\circ}$.

The fraction of wave energy absorbed inside a magnetic surfare, for the case of a Gaussian beam with a full half-intensity width of $5^{\circ}$, is shown in Fig. 7 as a function of the surface volume for the two launching geometries of Fig. 6. In both cases the wave is almost completely absorbed in a single pass. The absorbed power density profile, averaged over the magnetic surface, is shown in Fig. 8 for the case of top launching. The absorbing region is near the center of the torus, even though the central value of the electron cyclotron frequency is more than $50 \%$ larger than the wave frequency. Its position can be easily controlled by adjusting the angle $\beta$, since by increasing its value the absorbing layer is shifted towards the outside of the torus.

To obtain strong absorption at lower values of $T_{\mathrm{e}}$ one must either increase the value of $\alpha$ (i.e., $N_{i}$ ) or lower that of $B_{0}$. The first method is 
described in Fig. 9 for the case of horizontal launching. Here we assume that the rf power is turned on with a value of $\alpha \approx 65^{\circ}$, when $n_{e}(0)=$ $4.5 \times 10^{14} \mathrm{~cm}^{-3}$ and $T_{c}(0)=5 \mathrm{keV}$. These are plasma conditions that one can safely predict for CIT with only ohmic licating. Then, as $T_{e}$ increases, the value of $\alpha$ is decreased and that of $n_{e}$ is increased to the values of Fig. 6 in such a manner that the conditions for total single pass absorption are satisfied, as shown in Fig. 9.

The second method is described in Fig. 10 for the case of top launching. Here we assume that the if power is turned on with a value of $\alpha \approx 12^{\circ}$ when $B_{o}=80 \mathrm{kG}, T_{e}(0)=4 \mathrm{keV}$, and $n_{e}(0)=7 \times 10^{14} \mathrm{~cm}^{-3}$. Again, these are plasma conditions easily attainable in CIT with only ohmic heating. The extraordinary electron cyclotron wave is completely absorbed by such a plasma, with a well-localized power deposition profile, as shown in Fig. 11. In this heating scenario we assume that, as $T_{e}$ increases, the values of $B_{o}$ and $n_{e}$ are risen to the final values of Fig. 6 in such a manner that total single pass absorntion is achieved with constant value of $\alpha$, as shown in Fig. 10. The power deposition remains well localized with a profile that changes from the shape of Fig. 11 to that of Fig. 8.

In both heating schemes the wave is absorbed by suprathermal electrons. Their energy, given by Eq. (3), is $\approx 5 T_{e}$ and, in the range of plasma parameters considered for CIT, it is much smaller than the Dreicer critical energy. Since the relaxation time of these resonant clecirons is also much smaller than the plasma confinement tirne in CIT, the absorption of wave entrgy results in plasma bulk heating, which is not much different from ohmic heating. Note also that, since the wave energy is released to suprathermal electrons, this type of electron heating is also suited for current profile control.

Of the two heating schemes described above, the second (Fig. 10) has two major advantages. The first is tnat, by starting the discharge during a rising $B_{o}$, one extends the burn time, inevitably very short in any compact device. The second advantage is more important and has to do with the initial polarization of the wave which, to couple to the extraordinary mode, must possess the right degree of ellipiicity. While in the first heating scenario (Fig. 9) the initial polarization changes drastically during the heating pulse, from close to circular to almost linear, in the second scenario it remains nearly constant and, more importantly, close to linear. In this case, if a linearly polarized wave is launched with the electric field perpendicular to the local magnetic field, less than $5 \%$ of the wave energy is coupled to the ordinary mode, which is not completely absorbed 
in a single pass. This simplifies enormously the launching structure. We can envision a simple antenna, where by bouncing the wave on a plane mirror whose position can be changed during the heating pulse, one can control the elcctron distribution by simply adjusting the angles $\alpha$ and $\beta$.

In summary, the plasina absorption of extraordinary waves with a frequency of $190 \mathrm{GHz}$ can be used for anxiliary heating of ClT with a torvidal magnetic field of $105 \mathrm{kG}$. This type of plasma heating leads to a very simple method of profile control, where by adjusting the wave's initial direction one can control the electron power deposition in both the physical and the velocity space.

\section{Conclusion}

In conclusion, we have investigated the damping of electron cyclotron waves in dense and hot plasmas by taking into account high order Larmor radius terms in the wave dispersion relation. We have shown that the strong reduction caused by FLR effects on the damping of extraordinary waves with perpendicular propagation and frequency around the electron cyclotron frequency becomes insignificant at large values of the parallel component of the refractive index.

We have shown that ECH at downshifted frequency can be successfully used for auxiliary heating of CIT. A simple heating scenario has been described where a linearly polarized wave is launched from the top of the plasma torus. It has been shown that with a wave frequency of $190 \mathrm{GHI} z$ it is possible to bring to thermonuclear ignition a dense, ohmic CIT plasma with a toroidal magnetic field of $105 \mathrm{kG}$ and a central density of $1 \times 10^{15} \mathrm{~cm}^{-3}$. One of the many advantages offered by this heating scheme is the control of the power deposition profile which is achieved by simply adjusting the wave's launching direction.

These results prove that ECH at downshifted frequency constittites a feasible alternative to ICRF for auxiliary heating in CIT. Wave sources with frequency of $190 \mathrm{GHz}$ are not at present commercially available. Nevertheless, recent impressive advances in the development of both gyrotrons ${ }^{10}$ and free-electron lasers ${ }^{11}$ give confidence on a favorable solution of this technological issue.

\section{Acknowledgment}

This work was supported by U.S. Department of Energy Contract No. DE-AC02-76-CHO-3073. 


\section{Appendix: dielectric tensor coefficients}

The coefficients on the r.h.s. of Eq. (2) are given by:

$$
a_{11}=a R S \sum_{s= \pm 1}(1+s / \xi) F\left(p_{s}\right) \text {, }
$$

$$
\begin{aligned}
a_{13}= & a R S\left(\omega / \omega_{c}\right) \sum_{s= \pm 1}\left[p_{s}+s\left(p_{s}+2 s q\right) / \xi+3 s q / \xi^{2}\right] F\left(p_{s}\right) \\
a_{33}= & a R S\left(\omega / \omega_{c}\right)^{2} \sum_{s= \pm 1}\left[p_{s}^{2}+s p_{s}\left(p_{s}+4 s q\right) / \xi+6 s q\left(p_{s}+s q\right) / \xi^{2}\right. \\
& \left.+12 s q^{2} / \xi^{3}\right] F\left(p_{s}\right) \\
b_{11}= & a R S\left(R / N_{\|} \mu\right)\left(\omega / \omega_{c}\right)^{2} \sum_{s= \pm 1} s\left(1+3 s / \xi+3 / \xi^{2}\right) F\left(p_{s}\right) \\
b_{13}= & a R S\left(R / N_{\| \mu} \mu\left(\omega / \omega_{c}\right)^{3} \sum_{s= \pm 1} s\left[p_{s}+3 s\left(p_{s}+s q\right) / \xi+3\left(p_{s}+4 s q\right) / \xi^{2}\right.\right. \\
& \left.+15 q / \xi^{3}\right] F\left(p_{s}\right), \\
b_{33}= & a R S\left(R / N_{\|} \mu\right)\left(\omega / \omega_{c}\right)^{4} \sum_{s= \pm 1} s\left[p_{s}^{2}+3 s p_{s}\left(p_{s}+2 s q\right) / \xi\right. \\
& \left.+3\left(p_{s}^{2}+8 s q p_{s}+4 y^{2}\right) / \xi^{2}+30 q\left(p_{s}+2 s q\right) / \xi^{3}+90 q^{2} / \xi^{4}\right] F\left(p_{s}\right) \\
d_{11}= & a R S\left(R / N_{\mid} \mu\right)^{2}(5 / 8)\left(\omega / \omega_{c}\right)^{4} \sum_{s= \pm 1}\left(1+6 s / \xi+15 / \xi^{2}+15 s / \xi^{3}\right) F\left(p_{s}\right) \\
d_{13}= & a R S\left(R / N_{\|} \mu\right)^{2}(5 / 8)\left(\omega / \omega_{c}\right)^{5} \sum_{s= \pm 1}\left[p_{s}\left(1+6 s / \xi+15 / \xi^{2}+15 s / \xi^{3}\right)\right. \\
& \left.+2(q / \xi)\left(2+15 s / \xi+45 / \xi^{2}+105 s / 2 \xi^{3}\right)\right] F\left(p_{s}\right) \\
d_{33}= & a R S\left(R / N_{\| \mu}\right)^{2}(5 / 8)\left(\omega / \omega_{c}\right)^{6} \sum_{s= \pm 1}\left[p_{s}^{2}\left(1+6 s / \xi+15 / \xi^{2}+15 s / \xi^{3}\right)\right. \\
& +4(q p s / \xi)\left(2+15 s / \xi+45 / \xi^{2}+105 s / 2 \xi^{3}\right)+10(q / \xi)^{2}(2+18 s / \xi \\
& \left.\left.+63 / \xi^{2}+84 s / \xi^{3}\right)\right] F\left(p_{s}\right), \\
c_{i j}= & -4 b_{i j}\left(\omega_{c} \Rightarrow 2 \omega_{c}\right), \\
f_{i j}= & -(128 / 5) d_{i j}\left(\omega_{c} \Rightarrow 2 \omega_{c}\right), \\
g_{i j}= & (243 / 5) d_{i j}\left(\omega_{c} \Rightarrow 3 \omega_{c}\right),
\end{aligned}
$$

where the symbol $b_{i j}\left(\omega_{c} \Rightarrow 2 \omega_{c}\right)$ means that $\omega_{c}$ must be replaced by $2 \omega_{c}$ in $b_{i j}$. The various quantities in these expressions are:

$a=\pi\left(\omega_{p} / \omega\right)^{2} / 4 N_{\|}^{2} K_{2}(\mu) \exp (\mu), \mu=m c^{2} / T_{e}, K_{2}(\mu)$ is the McDonald function, $q=R /\left(1-N_{\|}^{2}\right), \xi=\mu N_{\|} R /\left(1-N_{\|}^{2}\right), R=\left[\left(\omega_{\mathrm{c}} / \cdot \mathcal{\prime}\right)^{2}-1+N_{\|}^{2}\right]^{1 / 2}$, 
$S$ is a step fiunction, i.e., $S=1$ for $R^{2} \geq 0$ and $S=0$ for $R^{2}<0$, $F\left(\rho_{s}\right)=\exp \left[-\mu\left(\gamma_{s}-1\right)\right], \gamma_{s}=\left(1+p_{s}^{2}\right)^{1 / 2}$, and $p_{s}$ is a solution of

$$
\left(1+p_{s}^{2}\right)^{1 / 2}-\omega_{c} / \omega=N_{\|} p_{s},
$$

i.e., $p_{s}=\left[N_{\|}\left(\omega_{c} / \omega\right)+s R\right] /\left(1-N_{\|}^{2}\right)$. 


\section{References}

1 I. Fidone, G. Giruzzi, and E. Mazzucato, Phys. Fluids 28, 1224 (1985).

2 E. Mazzucato, I. Fidone, G. Giruzzj, and V. Krivenski, Nuclear Fusion 26, 3 (1986).

3 I. Fidone, G. Giruzzi, V. Krivenski, L. F. Ziebsll, and E. Viazzucato, Phys. Fluids 29, 803 (1986).

${ }^{4}$ E. Mazzucato, I. Fidone, G. Giruzzi, and V. Krivenski, Ilasma Physics anci Controlled Fusion 38, 1515 (1986).

5 M. Bornatici, F. Engelmann, and G. Lister, Phys. Fluids 22, 1664 (1979).

6 J. Schmidt, G. Bateman, D. Blackfield, L. Bromberg, C. Bushnell, J. Citrolo, D. Cohn, P. Colestock, C. Flanagan, M. Greenwald, W. Houlberg, M. Hughes, D. Ignat, R. Izzo, S. Jardin, G. Kerbel, L. P. Ku, G. KuoPetravic, B. Lipschultz, B. Montgomery, R. Parker, C. Paulson, Y-K. M. Peng, M. Petravic, C. K. Phillips, M. Phillips, N. Pomphrey, D. Post, F. Puhn, T. Shannon, J. Sheffield, D. Sigmar, D. Strickler, D. Swain, G. Swanson, R. Thome, A. 'Todd, N. Uckan, R. White, S. Wolfe, and K. Young, in Plasma Physics and Controlled Nuclear Fusion Research 1986 (Proc. 11th Int. Conf., Kyotu,1986), IAEA, Vienna (in press).

7 I. Fidone, G. Giruzzi, V. Krivenski, and L. F. Ziebell, Nuclear Fusiors 26, 1537 (1986).

8 D. Post, G. Bateman, W. Houlberg, L. Bromberg, D. Cohn, P. Colestọck, M. Hughes, D. Ignat, R. Izzo, S. Jardin, C. Kieras-Phillips, L. P. Ku, G. Kuo-Petravic, B. Lipschultz, R. Parker, C. Paulson, Y-K. M. Peng, M. Petravic, M. Phillips, N. Pomphrey, J. Schmidt, D. Strickler, A. Todd, N. Uckar, R. White, S. Wolfe, and K. Young, "Physics Aspects of the Compact Ignition Tokamak," Princeton Plasma Physics Laboratory Report PPPI-2389 (1986), Physica Scripta (to be published).

${ }^{9}$ i. B. Bernstein, and L. Friedland, in Hanbook of Plasma Physics, edited by A. A. Galeev and R. N. Sudan (North-Holland, Amsterdam, 1984), Vol. I, p. 367.

10 K. E. Kreischer, A. Singh. S. E. Spira, and R. J. Temkin, Bull. Am. Phys. Soc. 31, 1462 (1986).

11 T. J. Orzechowski, B. Andersor, W. M. Fawley, D. Prosnitz, E. T. Schlarlemann, S. Yarema, D. Hopkins, A. C. Paut, A. M. Sessler, and J. Wurtle, Phys. Rev. Lett. 54, 889 (1985). 


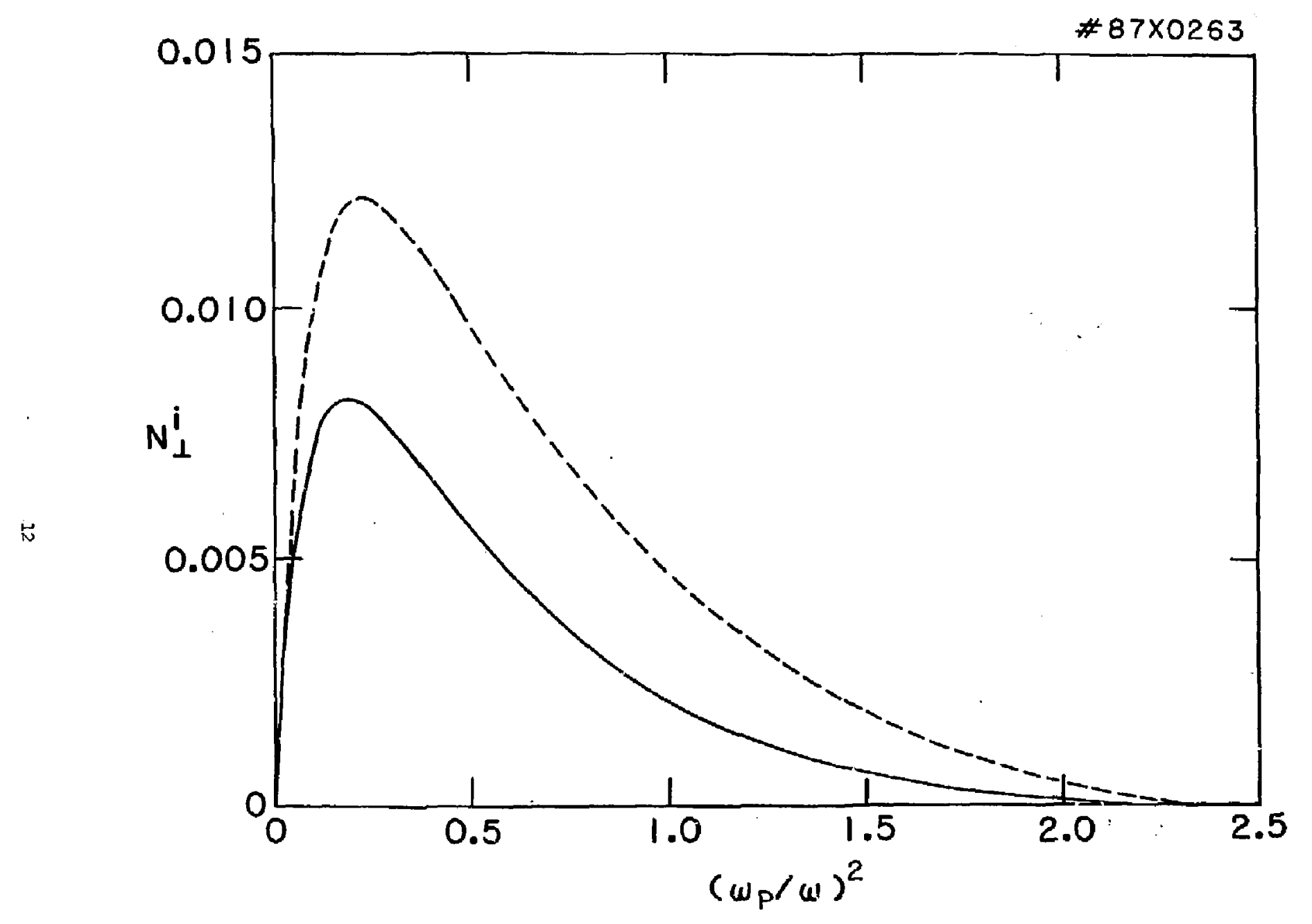

Fig. 1 Imaginary part of $N_{\perp}$ with (solid) and without (dash) high order FLR terms as a function of $\left(\omega_{p} / \omega\right)^{2}$ for $\omega_{\mathrm{c}} / \omega=1.3, T_{\mathrm{c}}=20 \mathrm{keV}$, and $N_{\|}=0$. 


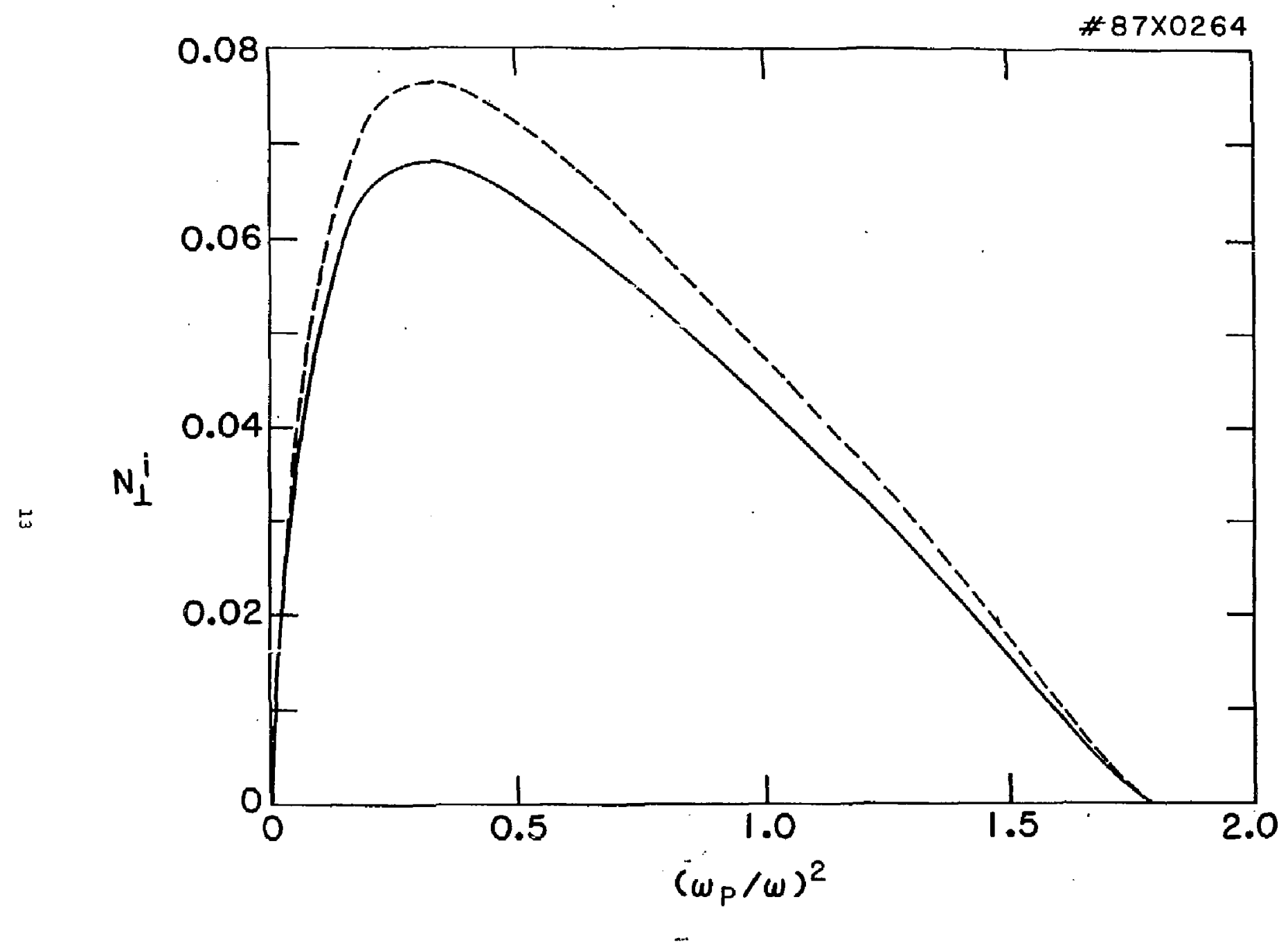

Fig. 2 Same as Fig. 1 with $N_{\mathrm{il}}=0.5$. 


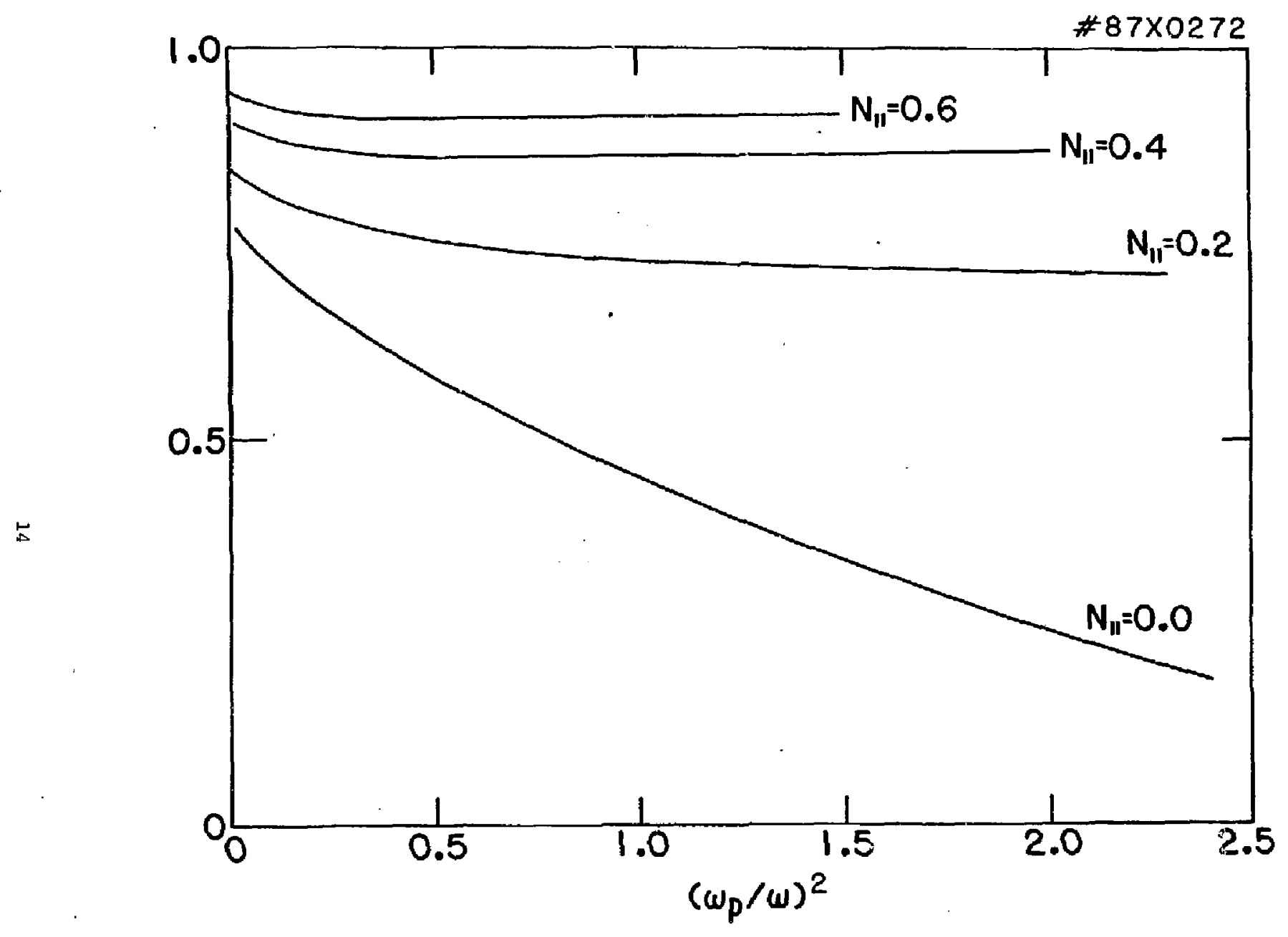

Fig. 3 Ratio of the imaginary parts of $N_{\perp}$ obtained with and without the high order FLR terms as a function of $\left(\omega_{p} / \omega\right)^{2}$ for $\omega_{c} / \omega=1.3, T_{e}=20 \mathrm{keV}$, and several values of $N_{\|}$. 


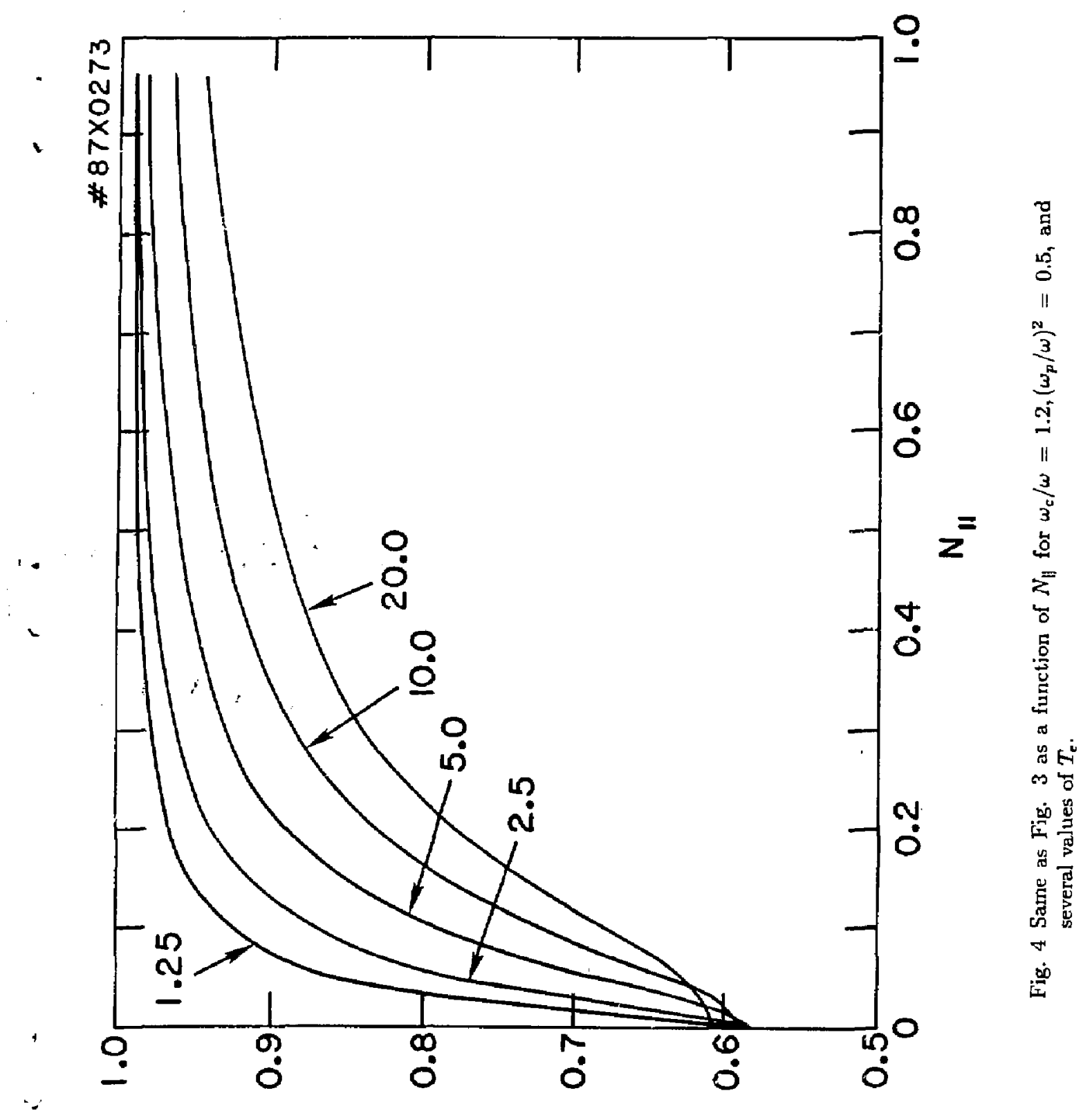




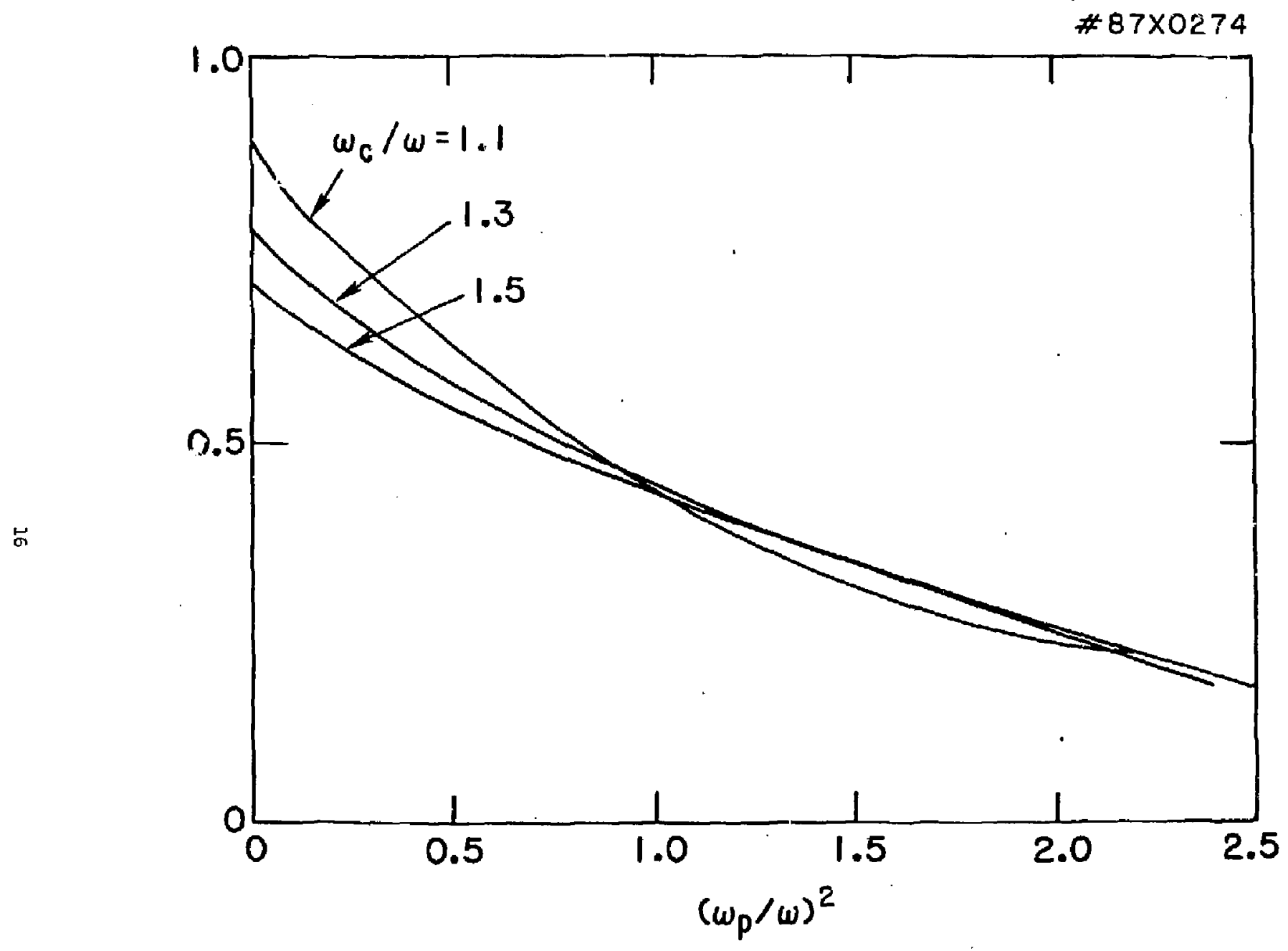

Fig. 5 Same as Fig. 3 for $\omega_{c} / \omega=1.1, T_{e}=20 \mathrm{keV}, N_{\|}=0$, and several values of $\omega_{c} / \omega$. 
\#87X0262

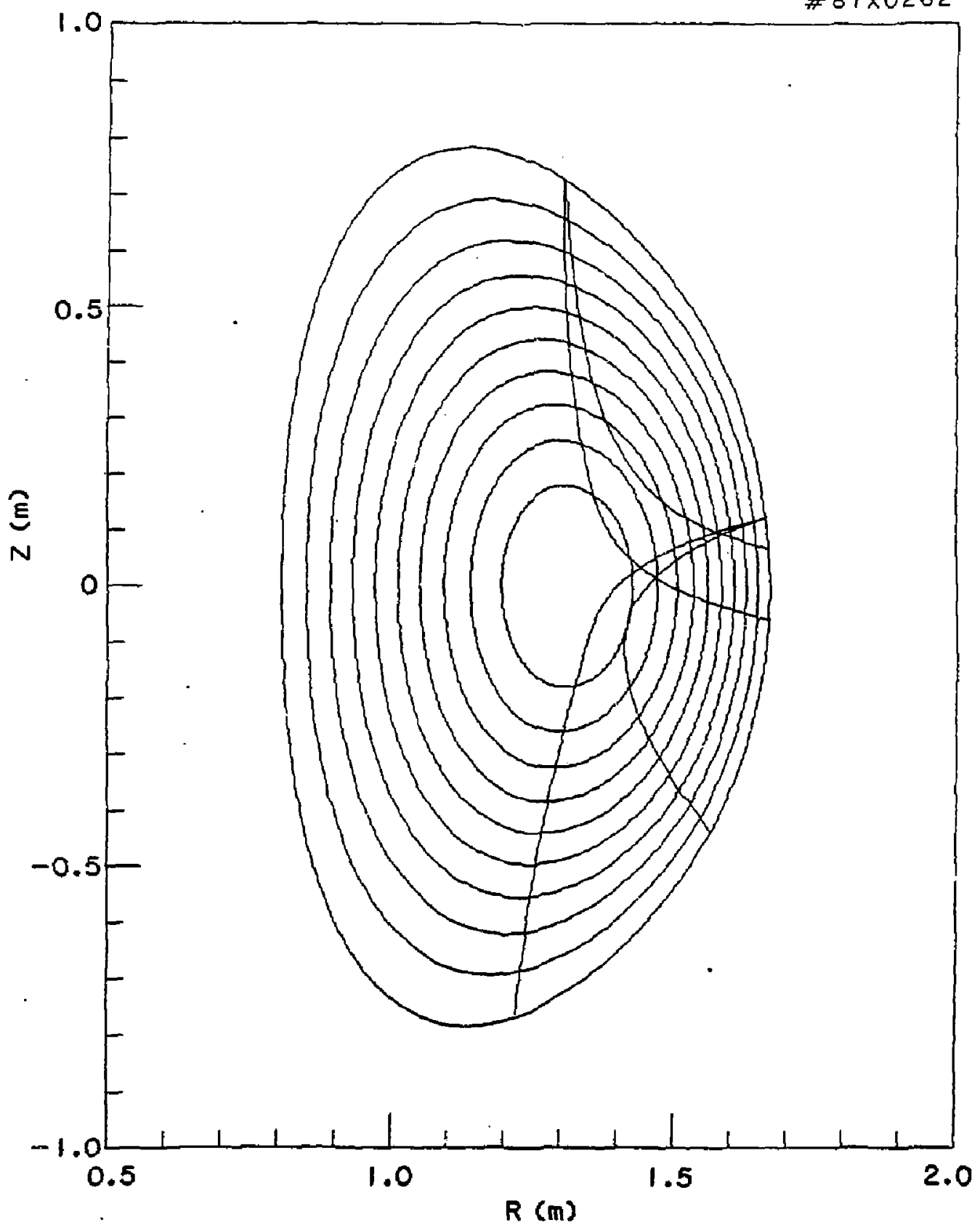

Fig. $6 \mathrm{CIT}$ magnetic configuration with $B_{0}=105 k G, I=8 \mathrm{MA}, n_{e}(0)=1 \times$ $10^{15} \mathrm{~cm}^{-3}, T_{\mathrm{e}}(0)=24 \mathrm{keV}:\langle\beta>=0.05$. Shown are also some ray trajectories for the extraordinary mode with $f=190 \mathrm{G} / z$, and $\alpha=12^{\circ}$. 


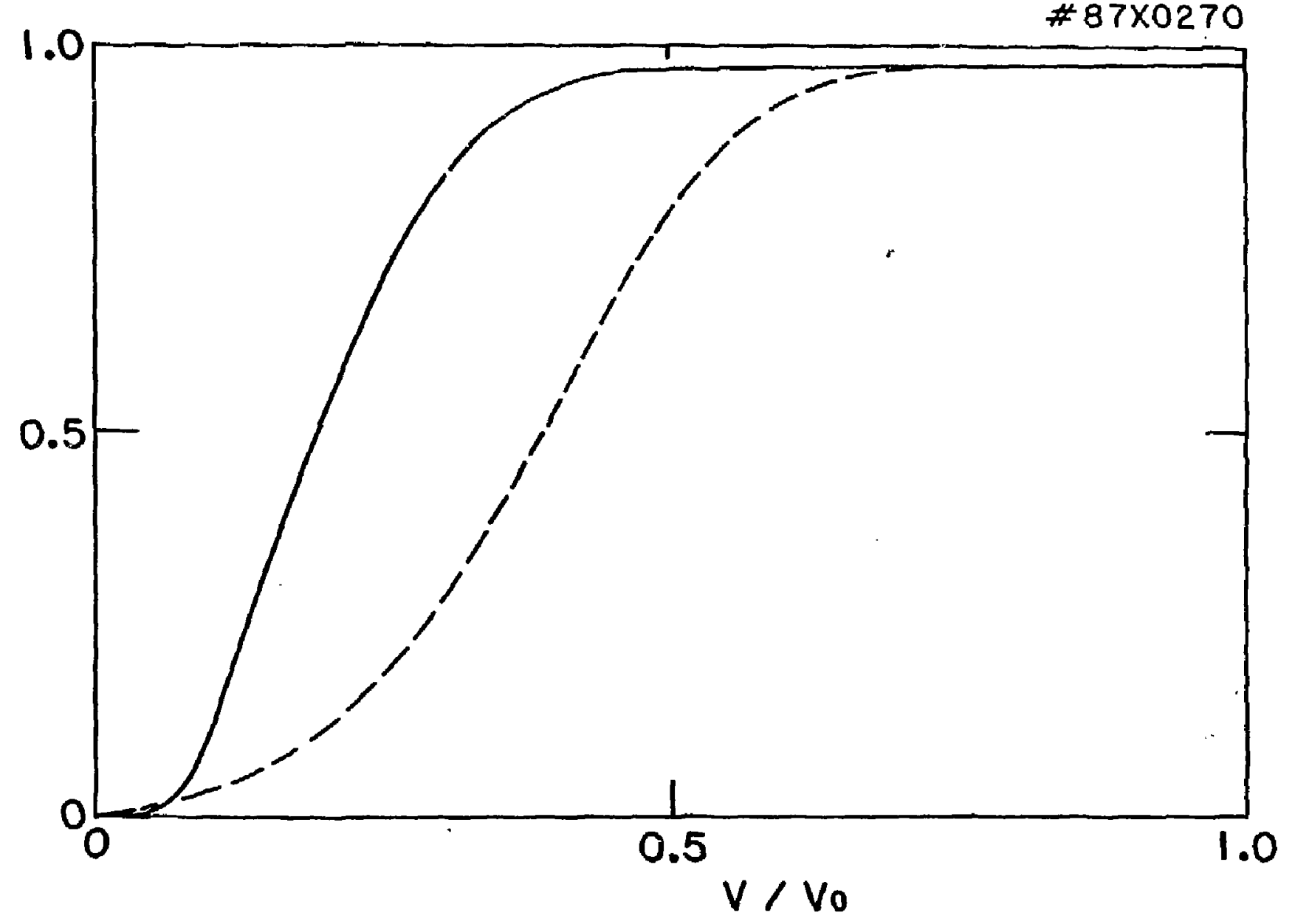

Fig. 7 Fraction of wave energy absorbed inside a magnetic surface as a function of the normalized surface volume for the two launching cases of Fig. 6 ; solid-top launching, dash-side launching. 


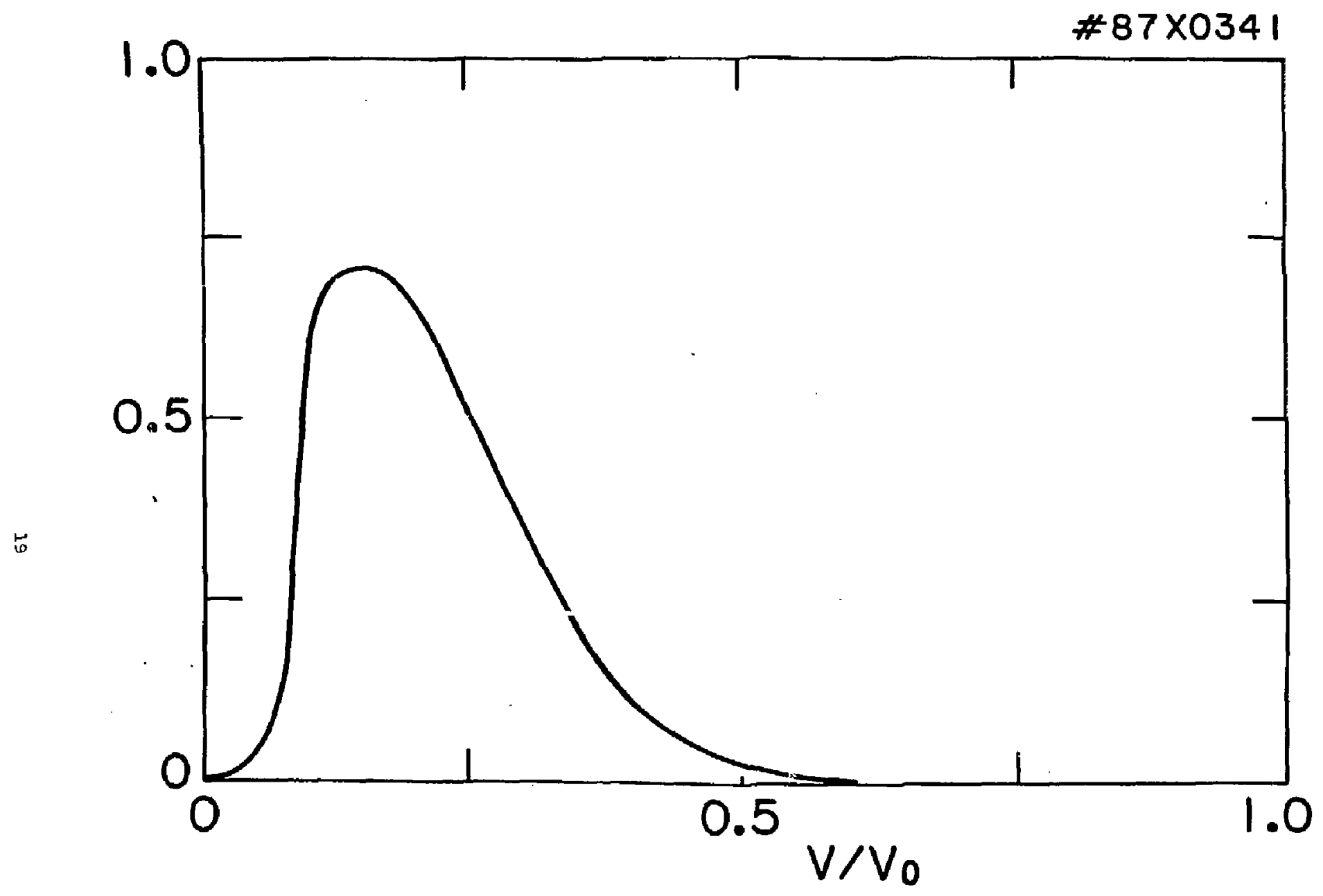

Fig. 8 Absorbed power density profile (surface average in arbitrary units) versus the magnetic surface volume for the case of top launching of Fig. 6. 
\#87X0260

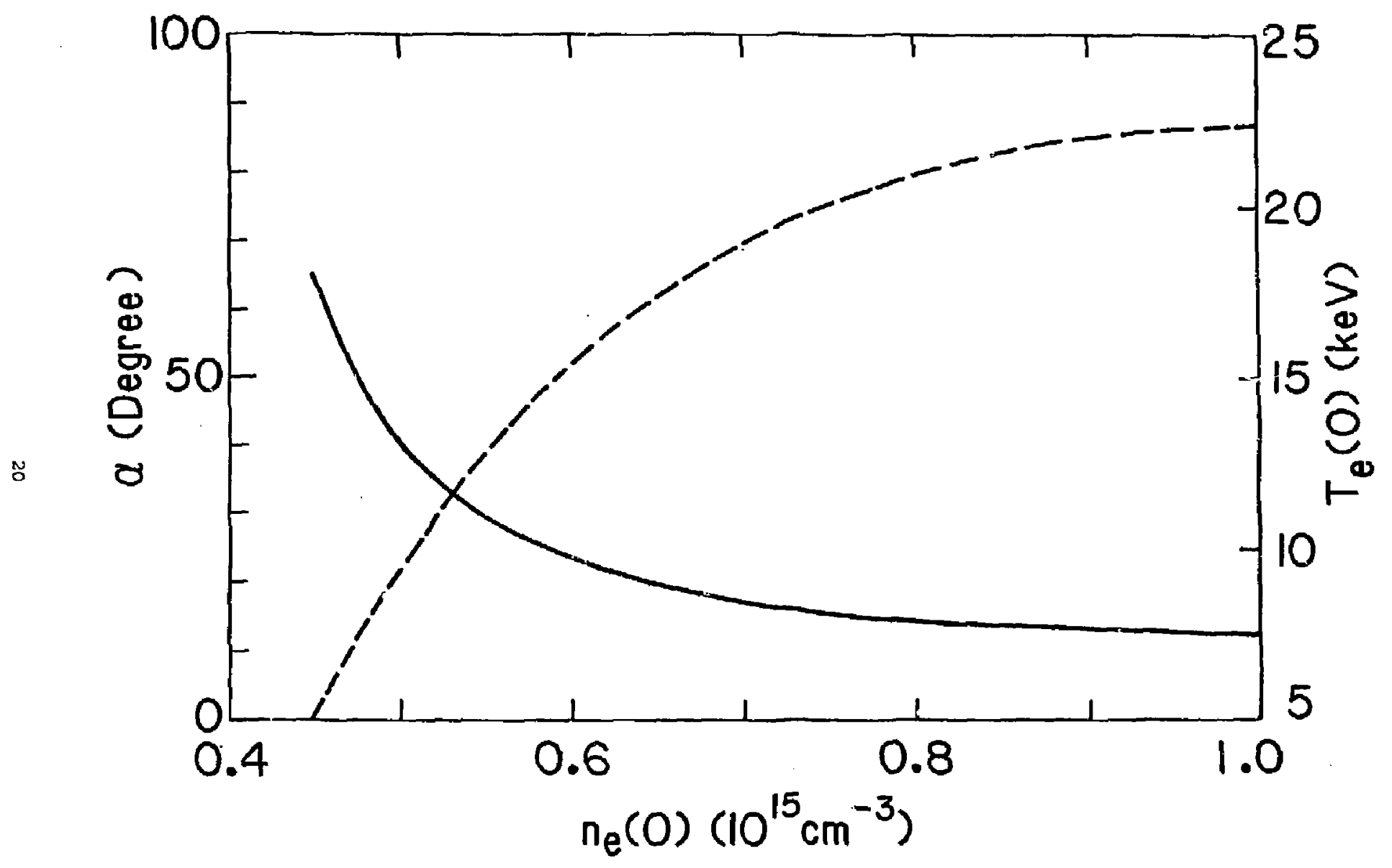

Fig. 9 Values of a (solid) and $T_{e}(0)$ (dash) as a function of $n_{e}(0)$ for complete single path absorption in the case of side launching with $B_{o}=105 k G$. 


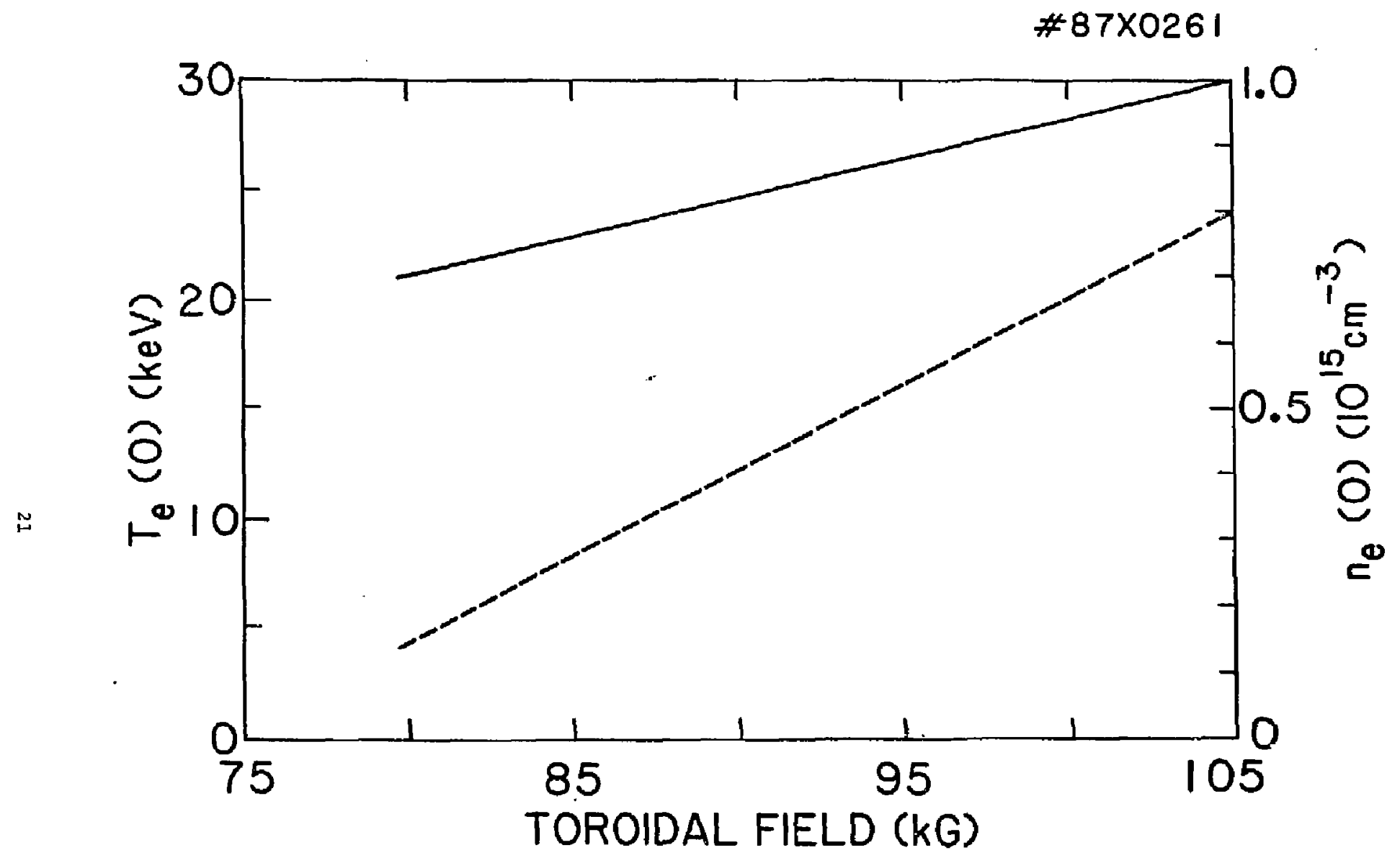

Fig.10 Values of $n_{e}(0)$ (solid) and $T_{c}(0)$ (dash) as a furiction of $B_{0}$ for complete single path absorption in the case of top launching with $\alpha \approx 12^{\circ}$. 


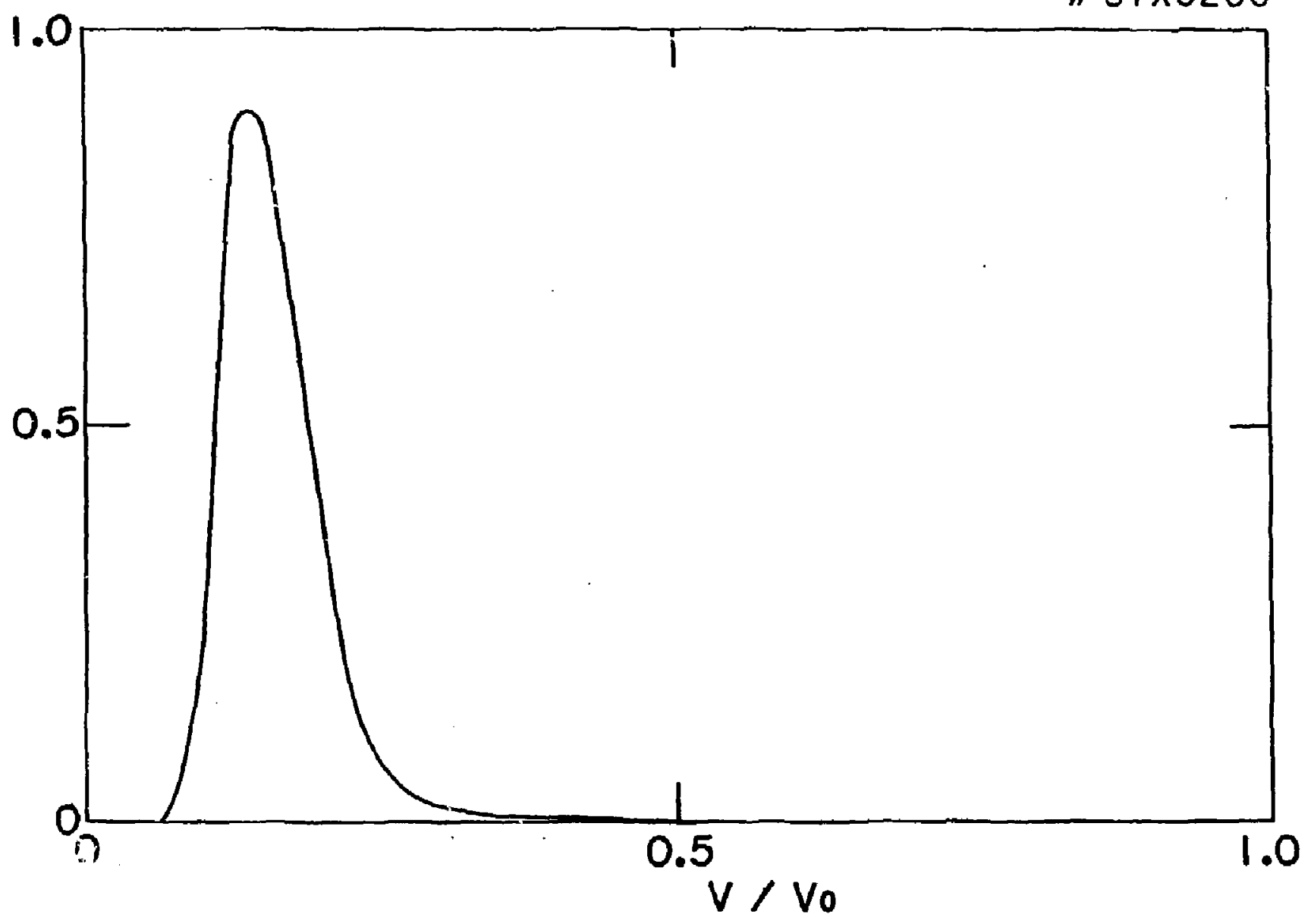

Fig.11 Same as Fig. 8 for $\alpha \approx 12^{\circ}, n_{\mathrm{e}}(0)=7 \times 10^{14} \mathrm{~cm}^{-3}, T_{\mathrm{e}}(0)=4 \mathrm{keV}$, and $B_{0}=80 \mathrm{kG}$. 
Dr. Frank J. Paolonl, Univ of wollongong, AuSTRALIA Prot. M.H. Bronnon, Univ SyJney, AuSTRALIA

Plasine Research Lab., Australian nat. Univ., AUSTRALIA

Prof, 1,R. Jonas, FIinders InIv., RUSTRAL iA

Praf. F. Cap. Inst theo Fhys, AUSTRIA

Prof. M. Helndlor, Institut fur Theoretlsche Physlk, AUSTRIA

M. Goossens, Astronomisch I instituut, BELGIUM

Ecolo Royale Milltaire, Lab de Phys Plasmas, BELGIUM

Com. of European, Dg XII fusion Prog, BELGIUM

Prof. R. Eoucique, Loboratoriun voor Natuurkunde, gELGILm

Dr. P.H. Sakanska, Uniy Estadual, BRAZIL

Instituto De Pesquisas Espaclasi-IMPE, ERMZIL

Library, Atomic Enargy of Canada LImlted, CNNADA

Dr. M.P. Bochynskl, MPB Technologies, InC., CANADA

Dr. H,M. Skarsgard, Unlv of Saskatchewan, CANNDA

Dr. H. Bernard, University of British Columbla, CaHADA

Prof. J. Teichnenn, Univ. of Montreal, CANAOA

Prof. S.R. Sreanivasan, University of Calgary, CANASA

Prof. Tudor W. Johnston, INRS-Energle, CANADA

Dr. C.R. James, UnIV. of Alberta, CNHMOK

Dr. Peter Lukac, Komonskeno UnIV, CZECHOSLOVAKIA

The LIbrarian, Culhem Laboratory, ENGLANO

Mrs. S.A. Hutehlnson, JET LIbrary, ENGLNo

c. Mouttet, Lob. de Physlaue des Mll I eux lonlsós, FRAKCE

J. Radet, CEN/CADARACGE - Bat 306, FRANCE

Dr. Tom Mul, Mcadeny albllographic, hONG KONG

- Preprlnt Library, Cent Res I nst Phys, HUMGNRY

Dr. B. Oesgupta, Saha Inst, INIA

Dr. R.K. Chhejlanl, VIkrom Univ, IMolA

Dr. P. Kow, Institute for Plams Research, INOIA

Dr. Phillip Rosenau, Isroel Inst Tech, ISRAEL

Prof. S. Cuparne:, Tel -Avlv University, ISRAEL

LIbrarlan, Int'l Ctr Theo Phys, ITALY

Prof. G. Rostagnl, UnIv DI Padova, ITALY

MIss Clelis De Palo, Assoc EURATOH-ENEA, ITALY

Biblisteca, del CHR EURATOM, ITALY

Dr. H. Yamoto, Toshiba Res a Dov, JAPW

Prof. I. Kunakeml, Atomlc Enargy Res. Institute, JAPAH

Prot. KyoJl NIshlkawa, Univ of HIroshima, JAPAN

D I rec, Dept. Lg. Tokamak Ros. JAERI, JAPAM

Prot. 5atoshi Itoh, Kyushu University, JAPAN

Research Info Conter, Hagoyo Univorsity, JAPAN

Prof. S. Tanaka, Kyoto Univers!ty, JNPN

Library, Kyoto University, JAPAN

Prot. Nobuyukl I nowe, Usiversity of Tokyo, JAPN

5. MOF T, JAERI, JAPAY

M.H. KIm, Kored Advanced Energy Research Institute, KOREA

Prof. D.l. Chol, Ady. inst Scl \& Tech, KOREA

Prof. B.5. LII

- Institute of Plasen Physics, PEOPLE'S REPUBLLC OF CHINA

Librorian, Instituta of Phys.; PEOPLE'S REPLPLIC OF CHIMA

IIbrary, Tsing Hus UnIversity, PEOPLE'S REPUBLIC OF CHIMA
2. LI, SOuthwest Inst. Physles, PEOPLE'S REPUBLIC OF CHINA Prof. J.A.C. Cabral, Inst Superlar Toen, PORTUGAL Dr. Oetavian Petrus, AL I CUZA Unlversity, ROMANIA Dr. Johan de Villilers, Plasms Physlcs, AEC, SO AFRICA Prof. H.A. Hellberg, Inlversity of Natal, SO AFRICA Fusion Div. LIorary, JEN, SPAIN

Dr. Lennart Stentlo, Unlversity of IMEA, SWEDEN Library, Royal inst TWCh, SHEDEN

Prof. Hans wi thalmon, Cholmers Unly Tach, SWEDEN Cantre Phys des Plasmas, Ecole Palytech Fed, SWITZERLANO Blbllotheak, Fom-l nst voor Plasna-fysles, THE NETHERLANDS Dr. D.D. Ryutov, SIberian Aced SCl, USSR Dr. G.A. El Iseav, Kurchatov Instltute, USSR Dr. V.A. Glukhlkh, Inst Electro-Physical, USSR Or. V.T. Tolok, Inst. Phys. Tech, USSR Or. L.M. Korrlzhnykh, Institut Gen. Physies, USSR Prof. T.J.M. Boyd, Univ College $N$ Wales, WALES Nuel cor Res. Estabilishmant, Jull lach Lto., W. GERMWY Bloliothak, Inst. Fur Plasmaforschung, W. GERMAYY Dr. K. Senindier, Ruhr Universitat, W. GERMAYY ASDEX Roeding Rom, IPP/Max-Planck-Institut iur Plasmaphysik, W. GERAwr L1 brarian, Mox-Planck Institut, W. GERMANY Prot. Rok. Janer, Inst Phys, YugosLavia 